\title{
Cavitation Erosion Behavior on Thin Films of Polymer Blends Deposited Over Bronze Surfaces
}

\author{
ILARE BORDEASU ${ }^{1 *}$, ADRIAN CIRCIUMARU ${ }^{2}$, MIRCEA 0. POPOVICIU ${ }^{3}$, IOSIF LAZAR ${ }^{1}$, RODICA BADARAU ${ }^{1 *}$, IOAN GROZA ${ }^{1 *}$ \\ 1Politechnica University of Timisoara, 1Mihai Viteazul Blvd., 300222, Timisoara, Romania \\ 2Dunarea de Jos University of Galati, 47 Domneasca Str., 800008, Galati, Romania \\ ${ }^{3}$ Academy of Romanian Scientists, Timisoara Branch, 1 Mihai Viteazu Blvd., 300222, Timisoara, Romania
}

\begin{abstract}
The composite materials with polymeric matrix represent a great realization of chemical engineering. Their applications in all the industrial fields are dictated by their chemical, physical and mechanical properties. In the last 50 years the polymeric composite materials received a large use in the protection and repair work of the surfaces in contact with fluid currents of various natures. The scientific researches followed by the industrial use, show that the polymere films with certain composition and properties have an excellent behavior to chemical, abrasive and cavitation erosions. Because the moststressed machine details subjected to cavitation erosions are the blades, runners and impellers of hydraulic machines as well as the ship propellers, researchers are looking for the best polymers to increase the running time, or for the use in covering the zones with shallow erosions, during the repair work. In this direction is oriented also the present research, performed in the Cavitation Laboratory of the Timisoara Polytechnic University. The obtained cavitation erosion for specimens covered with different polymere films is compared with those realized in identical conditions, but for specimens without protection films. The results show that the films assure some increase in the resistance to cavitation erosion but the tested polymer layers have reduced adherence on the metal surface.
\end{abstract}

Keywords: polymeric blends, films, cavitation erosion behavior, pittings, SEM and EDAX analyzes

The alert rithm of industrial development, dependent on the electric energy production and the water transport determined the engineers, especially those involved in the scientific research, to look for solutions for increasing the life of the equipments with great influence upon this rithm, such as: hydraulic turbine runners, pump impellers and ship propellers. In the multitude of studies regarding the introduction of new manufacturing technologies, realized through computers using specialized programmes [1-3] and specific treatments $[4,5]$, there are targeted also the introduction of new materials such as composite materials bazed on polymers [6-9], for some details subjected to mechanical and hydrodynamic forces, the shape and integrity of those details being of great importance for the performance and the exploatation period of the whole machine. In the last periode, mixtures bazed on polymers are frequently used for covering the metalic details, both in manufacturing period or for repair works. Those films realize a good protection for the surface of details w orking in hydrodynamic fields (blades or runners of hydraulic turbines, ship propellers, the rings and disks of the forced duct valves, the internal surfaces of pipes) subjected to intense cavitation erosion [6-10]. To obtaine safe assurances, in the present work is analyzed for various materials the resistance to intense erosions, in laboratory devices using vibratory cavitation [10-12].

\section{Experimental part}

Investigated material

The polymer film was deposed using a laboratorymixer set for two regimes - one very slow in order to ensure the adhesion of liquid pre-polymer mixture to the metallic surface (bronze with $81.45 \% \mathrm{Cu}, 14.58 \% \mathrm{Sn}, 0.3639 \% \mathrm{Zn}$, $1.037 \% \mathrm{~Pb}, 0.6471 \% \mathrm{Fe}, 0.8489 \% \mathrm{Ni}, 0.0359 \% \mathrm{Mn}, 0.077$ $\% \mathrm{Si}, 0.0298 \% \mathrm{~S}$ ) and one fast to ensure the removal of excess polymer. The pre-polymer mixture is realised from an epoxy resin (EPIPHEN RE42-20- DE 4020) [13] and a vinylester epoxidized resin (SIRESTER VE 64-M-140) [14] first for its high adhesion to metals and the second for its ability to polymerize at elevated temperatures. Also, the polymer mixture was modified by adding collagen (viewed as an agent to increase the flexibility of the polymer film) and anorganic salts $\mathrm{BaCl}_{2}(0.02 \mathrm{~mol}), \mathrm{AgNO}_{3}(0.03 \mathrm{~mol})$ and $\mathrm{SCCl}_{3}(0.01 \mathrm{~mol})$, for the P1 material, and, respectively, $\mathrm{YCl}_{3}$ (each $0.01 \mathrm{~mol}$ ) for P2 material. All these inorganic salts were intended to ensure a metallic bond between the polymer and the metallic surfaces. The polymer mixture was obtained after a long term process (of about ten weeks, described in [15]) and before film application they were homogenuous mixtures with no observable aggregates.

The covering films are, in fact, realized from three layers of polymer. First layer is deposed on heated metal piece $\left(90^{\circ} \mathrm{C}\right)$ such as is expected the polymerization of vinylester epoxidized resin ensuring the close contact between prepolymer mixture and the metal sample. After centirfugation the sample is immersed into epoxy system hardener ensuring the polymerization of epoxy resin. Because of the elevated value of metal piece some pores into the polymer film are expected. The second layer application is different for the samples denoted as a and, respectively, as $\boldsymbol{b}$ (P1a, P2a and P1b, P2b). In the case of a probes the second layer is applied under the same conditions as the first layer (with heated sample) while for the $b$ type probe, the second layer is applied at room temperature.

SEM and EDAX analysis

Regarding SEM analysis of the polymer covered metal pieces there are not major differences (fig. 2a, 3a, 4a, and 5a). Machining traces are observable but also some dark spots are observable and their dimensions are about few hundred nano-meters. These dark spots could represent

\footnotetext{
*email: ilare.bordeasu@upt.ro, ilarica59@gmail.com, badarau.rodica@gmail.com, ioan.groza@upt.ro
} 


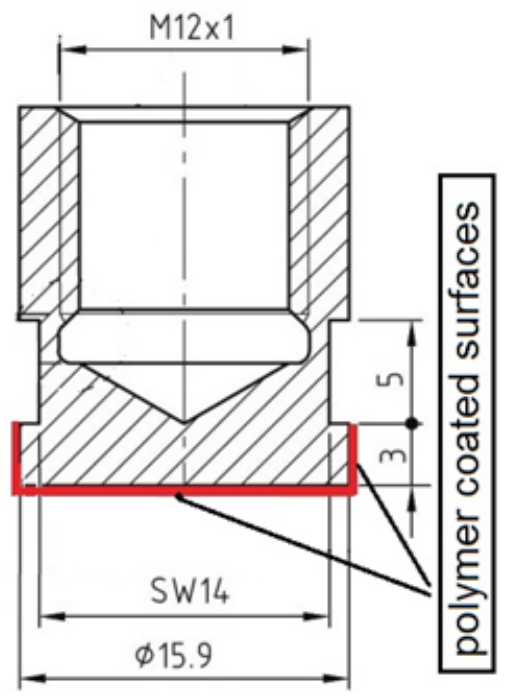

Fig. 1 Cavitation sample indication to the surfaces coated with polymer

films

nano-structures formed inside the polymer mixture due to some local chemical reactions between inorganic compounds. The EDAX analysis (performed together with the SEM analysis) reveals the presence of all the species into the metallic alloy and the verylow presence of Barium, Silver, Scandium and Yttrium thathad been placed into the polymer (fig. 2b, 3b, 4b, and 5b).

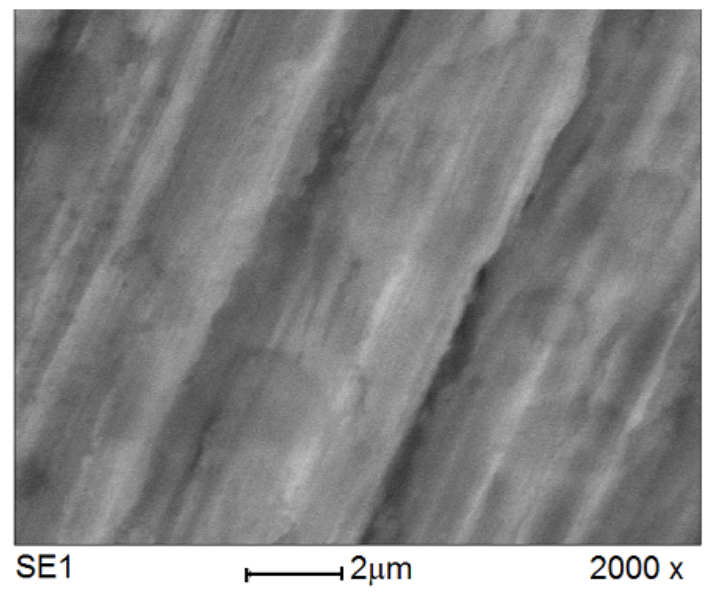

a)

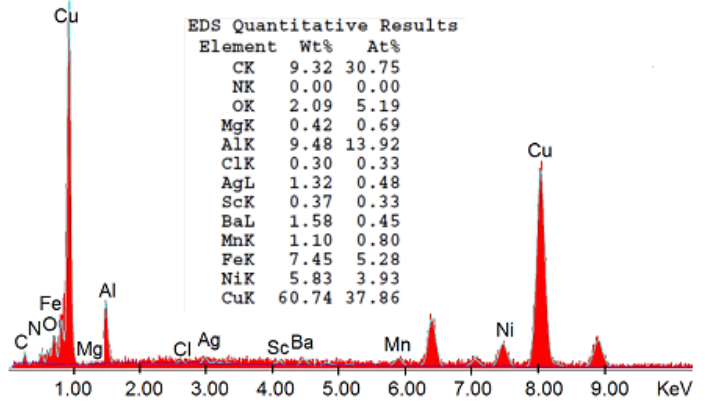

Fig. 2. EDAX analysis of $\mathrm{Pla}$ thin films

Raman analysis was performed on bulk materials (the two polymer mixtures molded and polymerized into cylindrical molds). The Raman microscope images, fig.6a and $7 a$, show some differences between the fracture surfaces of the two polymers (both polymer sticks were broken randomly) and the fracture area was investigated. In the case of P1 polymer the aspect is one of fish scales while the $\mathrm{P} 2$ polymer is more compact and presents some clusters of about 20 um transverse dimension. These differences might be explained by the presence of Scandium or Yttrium with effects on the polymerization mechanism. The Raman spectroscopy (fig. 6b and 7b) does not show differences between the two Raman spectra with the exception of the $3000 \mathrm{~cm}^{-1}$ peak, very well defined

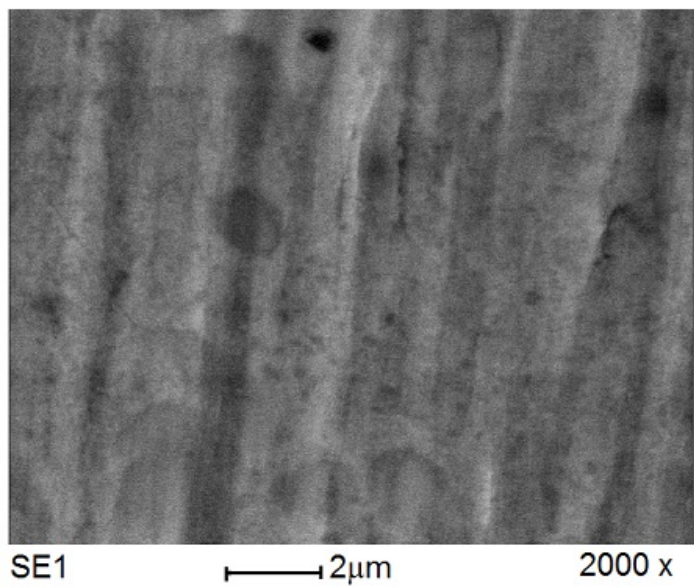

a)

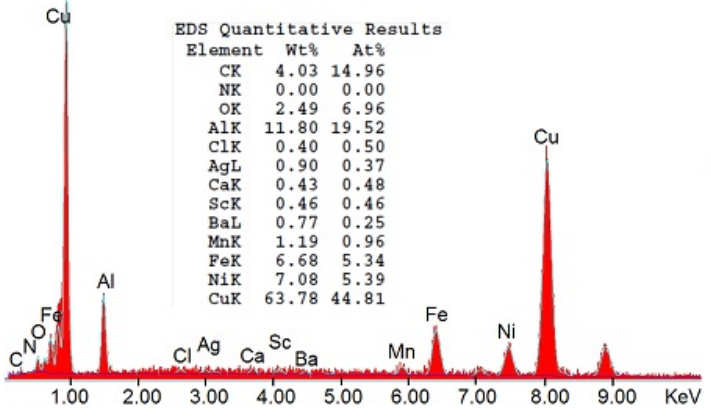

Fig. 3. EDAX analysis of $P 1 b$ thin films

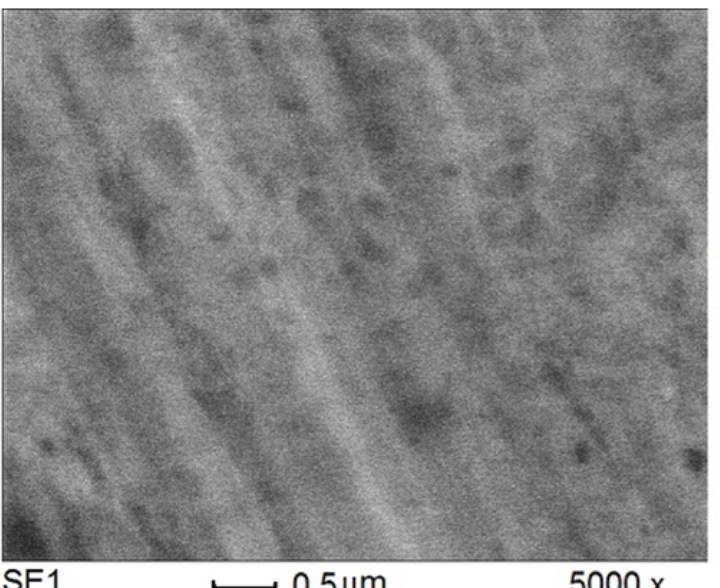

a)

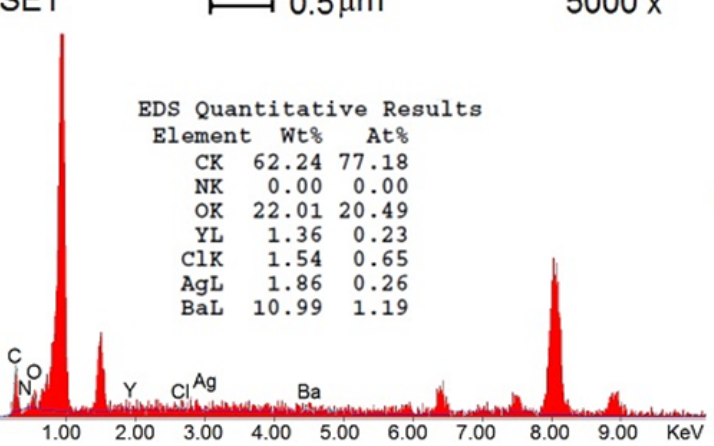

Fig. 4. EDAX analysis of $\mathrm{P} 2 \mathrm{a}$ thin films

for the P2 polymer and higher and dispersed for the P1 polymer. Regarding the Raman analysis of polymer films practically there are not differences between the four spectra $(6 c, d$ and $7 c, d)$ with the very well defined family of peaks centered around $1500 \mathrm{~cm}^{-1}$. These families of peaks are containing both the polymer mark (the highest peak of each family which can be observed also in the Raman spectra of the two polymers $6 \mathrm{~b}$ and $7 \mathrm{~b}$ ) and marks of the metallic substrate (formed by the other peaks of each family) which are identical for all the four samples. 

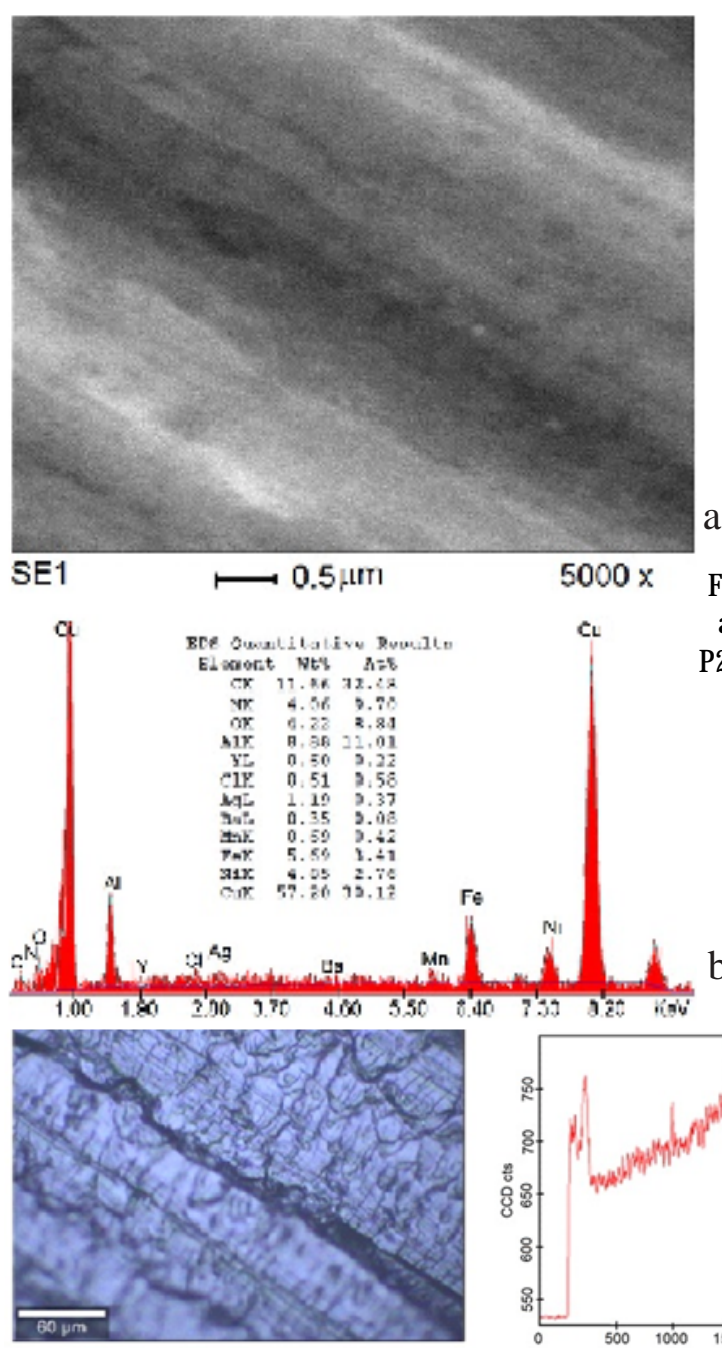

a) - Raman microscope image

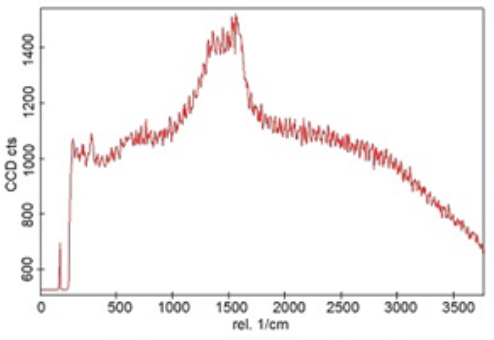

c) - Raman spectra of polymer P1a

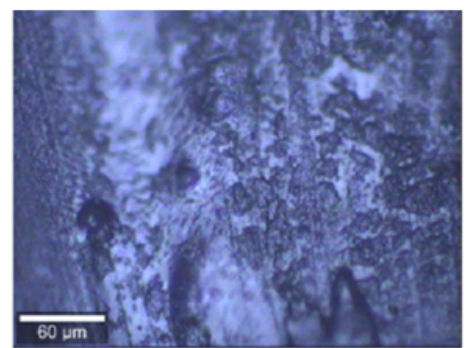

a) - Raman microscope image

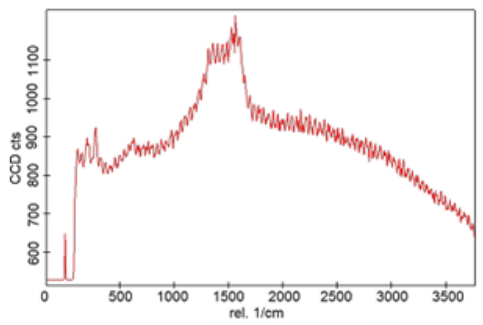

c) - Raman spectra of polymer $\mathrm{P} 2 \mathrm{a}$

Fig. 7. Raman microscope images and Raman spectra for P2 Polyme

\section{Cavitation test}

The experimental programme was conducted on the vibratory cavitation erosion device with piezoceramic crystals, a device with very intense cavitation, in the Timisoara Polytechnic University Cavitation Laboratory [16]. Both the device and the testing procedure fully respect the recommandation of the ASTM G32-2010 Standard [17]. There have been tested four specimens, two of them covered with $\mathrm{P} 1$ polymeric and the other two covered with polymeric P2. The comportment analysis was examined by optic mycroscopy and photographic images. The behavior of the two types of specimens was approximatelly indentical. The obtained images are presented in figure 810.

The images in figure 8 refer to the polymeric film noted with P1 and shows:

-after 5 min of cavitation exposure, the polymeric layer present perforations and areas with detachments in which water penetrate and sometimes also small vapor bubbles;

- after an exposure of $15 \mathrm{~min}$, the area with detachments, water penetration and bubble formation is increased;

- after 30 min of cavitation practically all the polymer layer is detached from the metal surface, a great part of it is broken, especially in the central zone, where the

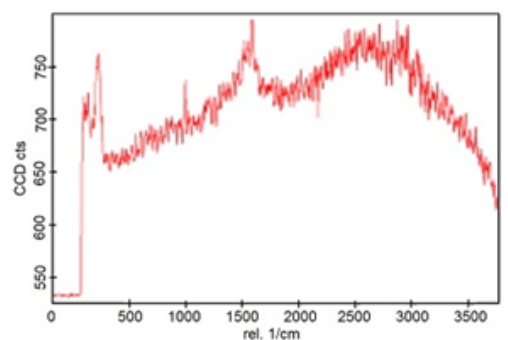

b) - Raman spectra for bulk modified polymer

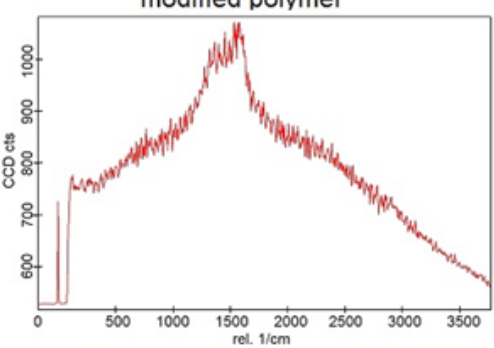

d) - Raman spectra of polymer P1b

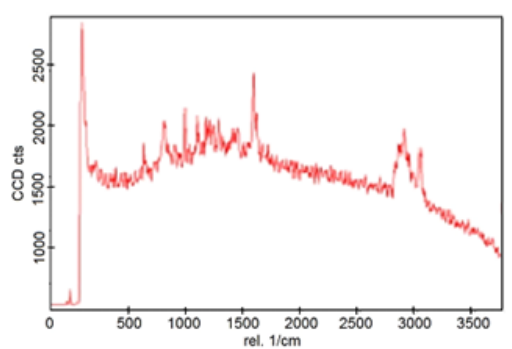

b) - Raman spectra for bulk modified polymer

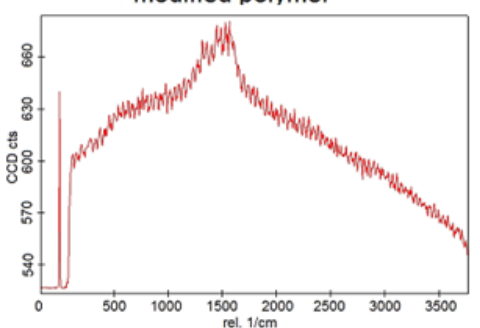

d) - Raman spectra of polymer P2b

http://www.revmaterialeplastice.ro
Fig. 6. Raman microscope images and Raman spectra for P1 polymer
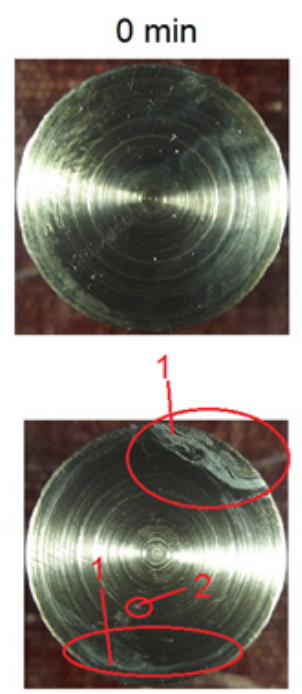

$15 \mathrm{~min}$
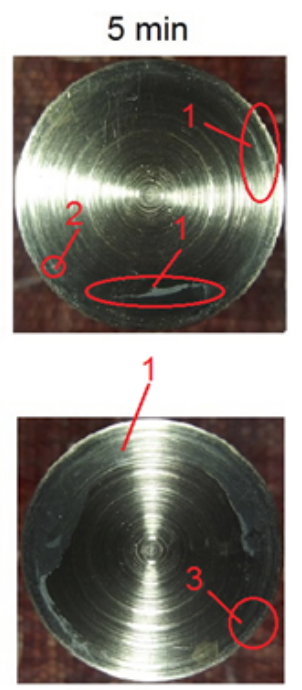

$30 \mathrm{~min}$

Fig.8. The cavitation behavior of the layers of epoxy resins Pla. The marked zones represent: 1-water and bubbles between the polymer film and the metal surface of the sample; 2-perforations in the polymer film; 3 - erosion in the metallic surface (cracks/pittings) 

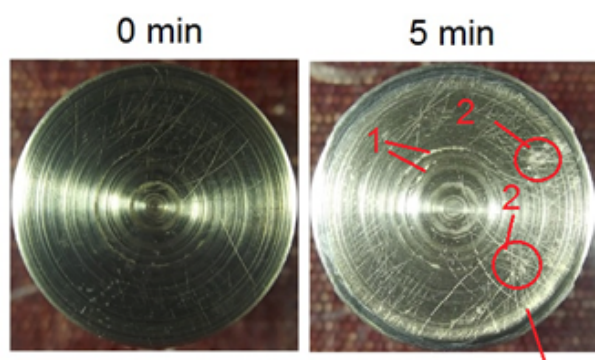

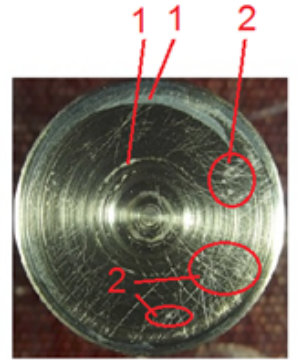

$15 \mathrm{~min}$

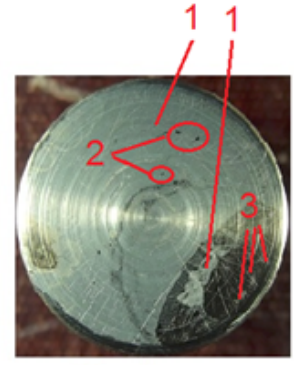

$30 \mathrm{~min}$

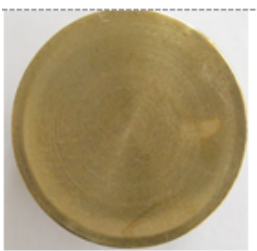

a)

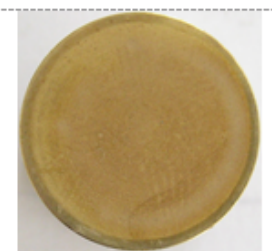

h)

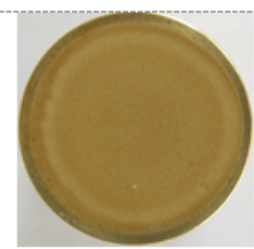

c)

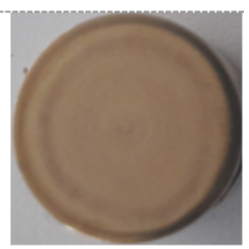

d)
Fig. 10 Comparative photographic images of the metal surface after 45 and $15 \mathrm{~min}$ exposure to the cavitation attack. a) specimen eroded surfaces after 45 min of cavitation with P1 polymer layer expulsion; b) specimen eroded surfaces after 45 min of cavitation

with P2 polymer layer expulsion; c) metal surface of the sample after $15 \mathrm{~min}$ of cavitation (without polymer layer); d) metal surface of the sample after $45 \mathrm{~min}$ of cavitation (without polymer layer).

Some differences are observable for the vibration cavitation behavior of the $\mathbf{a}$-type probes and $\mathbf{b}$-type probes and these differences might be interpreted from the middle layer effect namely in the case of the b-type probes due to the natural polymerization the pre-polymer mixtures closes the pores resulted into the structure of the first layer. Also, it is expected that the polymer film applied on the b-type probes to be more flexible than the one applied on the atype probes.

In order to use polymer materials, for the protection and repair works of the surfaces damaged by cavitation, such as hydraulic turbine blades, ship propellers and others, there are required new procedures to increase the adherence of the films on the metalic surfaces.

The initiations of perforations of the polymere films, during the first moments of cavitation show that the technology used in the preparation of the mixtures presents also other deficiencies that should solved.

\section{References}

1.NANU, S., BELGIU, G., SILEA, I., TOLERANCE DESIGN IN THE PLM ENVIRONMENT - AN EXPERT SYSTEM APPROACH, SOFA 2010 - $4^{\text {th }}$ International Workshop on Soft Computing Applications, Proceedings, 2010, pp. 255-258

2.VASILESCU, M.D., FLESER, T., Influence of technological parameters on the dimension of GEAR parts generated with PLA matherial by FDM 3D printing, Mat. Plast., 55, no. 2, 2018, pp. 247-251

3.LIE, I., BESCHIU, C., NANU, S., FPGA BASED SIGNAL PROCESSING STRUCTURES, SACI 2011-6th IEEE International Symposium on Applied Computational Intelligence and Informatics, Proceedings, 2011, pp. 439-444, DOI: 10.1109/SACI.2011.5873043

4.BORDEASU, I., MITELEA, I., SALCIANU, L., CRACIUNESCU, C. M., Cavitation Erosion Mechanisms of Solution Treated X5CrNi18-10 Stainless Steels, J OURNAL OF TRIBOLOGY-TRANSACTIONS OF THE ASME, Volume: 138, Issue: 3, 2016, Article Number: 031102, DOI: $10.1115 / 1.4032489$

5.MITELEA, I., GHERA, C., BORDEASU, I., CRACIUNESCU, C., Ultrasonic cavitation erosion of a duplex treated $16 \mathrm{MnCr} 5$ steel, International Journal of Materials Research, Vol. 106, No 4, 2015, p. 391-397

6.PAWLAK, A., GALESKI, A., Cavitation during tensile drawing of semicrystalline polymers, POLIMERY, vol.56, nr 9, 2011, p. 625.

7.CHOI, J-K., CHAHINE, G.L., Experimental and Numerical Study of Cavitation Erosion Resistance of a Polyurea Coating Layer, Fourth International Symposium on Marine Propulsors SMP'15, Austin, Texas, USA, June 2015

8.BRUJAN, E.A., AL-HUSSANY, A.F.H., WILLIAMS, R.L., P.R.WILLIAMS, P.R., Cavitation erosion in polymer aqueous solutions, Wear, Vol. 264, Issues 11-12, 2008, p. 1035-1042

9.TING, R. Y., Polymer effects on microjet impact and cavitation erosion, Nature, Volume 262, Issue 5569, 1976, pp. 572-573 10.*** https://www.belzona.com/en/products/2000/2141.aspx cavitation. For this reason, after a short period, the polymer films are detached from the surface, in the form of foils. 
11.BORDEASU, I., MITELEA, I., LAZAR, I., MICU, L. M., KARANCSI, 0. Cavitation Erosion Behaviour of Cooper Base Layers Deposited by HVOF Thermal Spraying, Rev. Chim. (Bucharest), 68, no. 12, 2017, p. 2914-2918

12.BORDEASU, I., MICU, L., MITELEA, I., UTU, I.D., PIRVULESCU, L.D., SIRBU, N.A., Cavitation Erosion of HVOF Metal-ceramic Composite Coatings Deposited onto Duplex Stainless Steel Substrate, Mat. Plast., 53, no. 4, 2016, pp. 781

13.***http://shop.polydis.ro/index.php/en/epoxy-resin/epiphen-re4020-catalizator-de-4020.htm
14.***http://www.sirindustriale.com/EN/CustomDocuments/SIRESTER \%20VE\%2064\%20M\%20140\%20tds\%20uk.pdf

15.LAZAR, I., BORDEASU, I., CIRCIUMARU, A., MITELEA, I., A Behavior of polymer thin films deposed on bronze surfaces at cavitation erosion, Mat. Plast. 55, no. 4, 2018, in press

16.LAZAR, I., BORDEASU, I., POPOVICIU, M. O., MITELEA, I., BENA, T., MICU, L. M., Considerations regarding the erosion mechanism of vibratory cavitation, KOD 2018, IOP Conf. Series: Materials Science and Engineering, 393,012040 doi:10.1088/1757-899X/393/1/012040, 2018 17.*** Standard method of vibratory cavitation erosion test, ASTM, Standard G32-2010

Manuscript received: 15.06 .2018 